\title{
Prognostic impact of chromosomal aberrations in Ewing tumours
}

\section{Hattinger*,,1,9, U Pötschger', M Tarkkanen, ${ }^{2,3}$, J Squire ${ }^{4,5}$, M Zielenska ${ }^{5,6}$, S Kiuru-Kuhlefelt ${ }^{2,3}$, L Kager ${ }^{7}$, P Thorner ${ }^{5,6}$, S Knuutila ${ }^{2,3}$, FK Niggli, PF Ambros', H Gadner ${ }^{7}$ and DR Betts ${ }^{8}$}

'CCRI, St. Anna Children's Hospital, A- 1090 Vienna, Austria; ${ }^{2}$ Department of Medical Genetics, Haartman Institute, University of Helsinki, FIN-000 I 4 Helsinki, Finland; ${ }^{3}$ Laboratory of Medical Genetics, Helsinki University Central Hospital, FIN-000 I 4 Helsinki, Finland; ${ }^{4}$ Ontario Cancer Institute and Medical Biophysics, Faculty of Medicine, University of Toronto, Toronto, Ontario M5G 2M9, Canada; ${ }^{5}$ Department of Laboratory Medicine and Pathobiology, Faculty of Medicine, University of Toronto, Toronto, Ontario M5G 2M9, Canada; ' Division of Pathology, Department of Pediatric Laboratory Medicine, Hospital for Sick Children, Toronto, Ontario M5G 2M9, Canada; ${ }^{5}$ St. Anna Children's Hospital, A-1090 Vienna, Austria; ${ }^{8}$ Department of Oncology, University Children's Hospital, CH-8032 Zürich, Switzerland

\begin{abstract}
Although greater than 50\% of Ewing tumours contain non-random cytogenetic aberrations in addition to the pathognomonic 22q 12 rearrangements, little is known about their prognostic significance. To address this question, tumour samples from I34 Ewing tumour patients were analysed using a combination of classical cytogenetics, comparative genomic and fluorescence in situ hybridisation. The evaluation of the compiled data revealed that gain of chromosome 8 occurred in $52 \%$ of Ewing tumours but was not a predictive factor for outcome. Gain of I q was associated with adverse overall survival and event-free survival in all patients, irrespective of whether the tumour was localised or disseminated (overall survival: $P=0.002$ and $P=0.029$; eventfree survival: $P=0.018$ and $P=0.010$ ). Loss of $16 q$ was a significant predictive factor for adverse overall survival in all patients $(P=0.008)$ and was associated with disseminated disease at diagnosis $(P=0.039)$. Gain of chromosome 12 was associated with adverse event-free survival $(P=0.009)$ in patients with localised disease. These results indicate that in addition to a $22 q 12$ rearrangement confirmation in Ewing tumours it is important to assess the copy number of Iq and 16q to identify patients with a higher probability of adverse outcome.

British Journal of Cancer (2002) 86, 1763 - 1769. doi:I0.1038/sj.bjc.6600332 www.bjcancer.com
\end{abstract}

(c) 2002 Cancer Research UK

Keywords: Ewing tumours; prognostic markers; molecular cytogenetics; Iq; 16q; chromosome 12

Skeletal and extraskeletal Ewing's sarcoma (ES) and peripheral primitive neuroectodermal tumours (pPNET) are characterised by a high expression of the CD99 antigen (Ambros et al, 1991) and the presence of the balanced translocation $\mathrm{t}(11 ; 22)(\mathrm{q} 24 ; \mathrm{q} 12)$ or related aberrations involving 22q12 (Aurias et al, 1983; Turc-Carel et al, 1983; Becroft et al, 1984; Whang-Peng et al, 1984). Therefore, small-blue-round-cell tumours of childhood and early adolescence that show high CD99 expression and the presence of a 22q12 aberration are often grouped under the term 'Ewing tumours' (ETs) (Ambros et al, 1991) or 'Ewing family of tumours' (EFTs) (Delattre et al, 1994).

The $\mathrm{t}(11 ; 22)(\mathrm{q} 24 ; \mathrm{q} 12)$ that is present in $85-90 \%$ of ETs (Mitelman et al, 2001) generates a chimeric fusion transcript between the EWS (22q12) and FLI1 (11q24) genes (Delattre et al, 1992; Zucman et al, 1992). In the remaining cases, the EWS gene is rearranged with other partners of the ETS oncogene family (for review see Sandberg and Bridge, 2000). In addition to the rearrangements involving 22q12, non-random chromosomal aberrations occur in more than $50 \%$ of cytogenetically analysed ETs (Sandberg and Bridge, 2000; Mitelman et al, 2001). Chromosome gain is the most frequent event, of which trisomy 8 is the most common found in

\footnotetext{
*Correspondence: CM Hattinger; CCRI, St. Anna Children's Hospital, Kinderspitalgasse 6, A - 1090 Vienna, Austria

${ }^{9}$ Current address: Laboratorio di Ricerca Oncologica, Istituti Ortopedici Rizzoli, Via di Barbiano I/ I 0, I - 40 I36 Bologna; E-mail: genetica.onc@ior.it Received 20 December 200I; revised 25 March 2002; accepted 27 March 2002
}

almost $50 \%$ of the cases, with gains of 2, 12 and 20 also being frequent non-random events (Mugneret et al, 1988; Kullendorff et al, 1999). Additional structural aberrations are less common than numerical changes, although unbalanced rearrangements involving chromosomes 1 and 16 are quite frequently seen. In the majority of these cases the net imbalance is gain of $1 \mathrm{q}$ with simultaneous loss of 16q (Mugneret et al, 1988; Douglass et al, 1990; Hattinger et al, 1996; Armengol et al, 1997; Stark et al, 1997; Kullendorff et al, 1999; Tarkkanen et al, 1999).

To date only the presence of metastases at diagnosis has constantly been reported to be a negative prognostic marker for ET patients (Jürgens et al, 1988; Terrier et al, 1996; Cotterill et $a l, 2000)$. In addition, in patients with localised disease, poor histological response to chemotherapy (Picci et al, 1997; Bacci et al, 2000), tumour volume (Jürgens et al, 1988; Koscielniak et al, 1992; Ahrens et al, 1999), primary tumour site and age less than 15 years at diagnosis have been variably associated with adverse clinical outcome (Cotterill et al, 2000).

Clinical implications of genetic changes in ETs are poorly understood. Type 1 EWS-FLI1 fusion transcripts were associated with better outcome in patients with localised disease compared to all other EWS fusion transcripts in few studies (Zoubek et al, 1994, 1996; de Alava et al, 1998). Recently, deletions of INK4A (9p21) and TP53 alterations (17p13) appeared to define small groups of patients with markedly poor outcome (Kovar et al, 1997; de Alava et al, 2000; Wei et al, 2000). Besides molecular genetic markers of possible prognostic value, increased copy number of chromosomes 8,12 , and of $1 \mathrm{q}$ and loss of $1 \mathrm{p}$ have been discussed to be associated with an advanced stage of disease, but with conflicting evidence as 
to whether they are associated with a poor clinical outcome (Douglass et al, 1990; Armengol et al, 1997; Maurici et al, 1998; Hattinger et al, 1999; Kullendorff et al, 1999; Tarkkanen et al, 1999). As ETs are rare all these previous studies were performed on small numbers of patients and could not reach firm conclusions with regard to the prognostic impact of the additional genetic aberrations.

To ascertain the clinical significance of the most frequent additional cytogenetic events in a large series of patients with ET, the present collaborative retrospective study was initiated. Genetic data from clinically well documented ET patients were collected and statistical analyses were performed in order to elucidate correlations between genetic and clinical parameters and to determine the influence of these parameters on the clinical outcome.

\section{PATIENTS AND METHODS}

\section{Patients and tumour specimens}

Genetic and clinical data were collected from a series of 146 patients with ET from four different centres (Helsinki, Toronto, Vienna, Zurich). Criteria for inclusion in the study were date of diagnosis between January 1983 and October 1999 and confirmed diagnosis of ET either by positive CD99 staining and/or the presence of a 22q12 rearrangement. Due to incomplete clinical and/or genetic data 12 patients were excluded from statistical analyses. Thus, 134 patients were included in the final study representing consecutive series of ET patients for each of the four centres: Helsinki (23 patients), Toronto (24 patients), Vienna (68 patients) and Zurich (19 patients).

The median age at diagnosis of ET was 13 years (range 4 months-37 years). Sixty-two patients were male $(46 \%)$ and 72 female $(54 \%)$. Chest wall $(n=15)$, pelvis $(n=14)$ and femur $(n=12)$ were the most frequent tumour sites at diagnosis in the 91 patients presenting with localised ET. The primary tumours of the 43 patients with disseminated disease at diagnosis were located most frequently in the pelvis $(n=15)$. Other tumour locations were found in less than 10 patients each. In 121 patients, tumour tissue at diagnosis was analysed, in four patients at both diagnosis and relapse, and in nine patients at relapse. Published chemotherapy regimens were applied to 120 patients: CESS- 81 and CESS-86+91P (Jürgens et al, 1988) in two patients each, CESS-86 (Jürgens et al, 1988) in 18 patients, CESS-91P (Jürgens, 1994) and Ewing-SF (Miser et al, 1987) in four patients each, EICESS-92 (Zoubek et al, 1996) in 40 patients, CWS (Koscielniak et al, 1992) in five patients, SSG IX (Elomaa et al, 2000) in 16 patients, SSG IX with reduced doses in one patient, Ewing-CA (Zielenska et al, 2001) in 24 patients and Ewing-IL (Stark et al, 1997) in three patients. One patient received palliative therapy (Wiklund et al, 1992) after first relapse only. Thirteen patients received chemotherapy regimens similar to published protocols used in the other centres, and one patient did not receive chemotherapy.

\section{Genetic analysis}

Tumour samples were analysed with complementary techniques. Chromosome analysis was performed in all four centres according to standard protocols (Dracopoli, 2001; ISCN, 1995). Cytogenetic data were available in 93 cases, of which 68 have been published in detail (Hattinger et al, 1996, 1999; Armengol et al, 1997; Stark et al, 1997; Tarkkanen et al, 1999; Zielenska et al, 2001).

Fluorescence in situ hybridisation (FISH) with centromere-specific probes for chromosomes $1,8,12,16$ and $\mathrm{X}$ were performed according to standard protocols (Dracopoli, 2001). To analyse the copy number of $1 \mathrm{p}$ FISH with probes D1Z1 (1q12) and
D1Z2 (1p36) was performed on 58 cases as described previously (Ambros et al, 1995; Hattinger et al, 1999, 2000). In 21 cases, DNA copy number changes were also determined by comparative genomic hybridisation (CGH) according to protocols described in detail previously (Armengol et al, 1997; Tarkkanen et al, 1999). For tumour DNA extraction, only tumour tissues containing more than $50 \%$ of tumour cells were accepted. In 11 cases without cytogenetic information, 22q12 rearrangements were studied by FISH using cosmid probes flanking the EWS breakpoint region at $22 \mathrm{q} 12$ according to a protocol previously described (Desmaze et al, 1994). EWS fusion transcripts were detected by RT-PCR in 59 cases as described (Delattre et al, 1994). In 45 patients, tumours were analysed by one of the methods (cytogenetics: 16, CGH: 5, FISH: 24), in 50 patients by two methods (cytogenetics and CGH, FISH or RT-PCR: 38; RT-PCR and CGH or FISH: 12), in 37 by three methods (cytogenetics and FISH and CGH or RT-PCR: 36; cytogenetics and CGH and RT-PCR: 1) and in two patients by all four methods. For the final evaluation of genetic parameters analysed, data obtained by all techniques were considered. In cases of disagreement between the results obtained by different techniques (two cases for dellp), this parameter was scored as not evaluable.

\section{Definition of genetic parameters for statistical evaluation}

Numerical aberrations were evaluated as 'gain' or 'loss' of whole chromosomes. For statistical analysis 'gain' was defined as 'plus one or more copies in addition to the appropriate somy of the analysed chromosome'. Isochromosomes were evaluated as 'gain'. In samples that were analysed only by FISH, the numbers of centromere-specific hybridisation signals per nucleus were evaluated for at least two different chromosomes and 100 to 200 nuclei per sample were counted. For touch preparations and cytospin slides at least $5 \%$ of the counted nuclei had to contain the abnormality. For paraffin embedded samples at least $7 \%$ of the nuclei had to show three hybridisation signals to be evaluated as trisomic (Zielenska et al, 2001). Structural aberrations were scored as 'present' or 'not present'.

\section{Statistical analysis}

Chi-square analysis was used to evaluate associations between clinical and genetic parameters and to test the consistency of data submitted from the different centres. Extent of disease at diagnosis (localised versus disseminated), tumour site (axial vs peripheral), age ( $<15$ years $v s \geqslant 15$ years), sex, gain of chromosomes 8 and 12 , gain of $1 \mathrm{q}$, deletion of $1 \mathrm{p}$ and loss of $16 \mathrm{q}$ were the parameters analysed. The probability of overall survival (OS) and event-free survival (EFS) were estimated according to the method of Kaplan-Meier (Kaplan and Meier, 1958). Duration of EFS was computed from the date of diagnosis of ET to the first occurrence of disease, defined as local or systemic relapse or death. For the analyses of OS only death was considered as an event. The clinical follow-up was collected up to 31st March 2000. Estimates of the 5-year-probability of OS and EFS were given together with their 95\% confidence intervals according to Dorey-Korn (Dorey and Korn, 1987). In addition, a proportional hazard model according to Cox (1972) was fitted. A stepwise selection procedure was used to identify the most important predictors among the genetic parameters, whereas all clinical parameters were forced to be included in the model. A $P$ value $\leqslant 0.25$, after adjustment for the effects of other variables, was required for inclusion and retention in the model. The relative risk of failure (RHR) and the associated 95\% confidence intervals were calculated with the coefficient and standard error from the Cox analyses. $P$ values were from the likelihood ratio test. Additionally, alternative models were compared on the basis of Akaike's (1972) information criterion. All analyses were 
carried out for the whole population as well as for the group of patients with localised ET.

\section{RESULTS}

\section{Genetic aberrations in Ewing tumours}

Information on 22q12 rearrangements was available for 109 cases. The classical $\mathrm{t}(11 ; 22)(\mathrm{q} 24 ; 12)$ and/or an EWS/FLI1 fusion transcript detected by classical cytogenetic analysis and/or RT-PCR, respectively, were found in 86 ETs (79\%). A further $11(10 \%)$ were positive for an EWS rearrangement by FISH using probes flanking the EWS breakpoint region on chromosome 22. Variant 22q12 rearrangements or deletions at $22 \mathrm{q} 12$ were found in 10 cases (9\%). Two cases were highly positive for CD99 only.

The most frequent numerical aberrations, irrespective of subgroup, were gains of chromosomes 8 and 12, present in 68 $(52 \%)$ and $36(27 \%)$ of evaluable cases, respectively. Non-random structural aberrations additional to $22 \mathrm{q} 12$ rearrangements, involved the long arms of chromosomes 1 and 16 in $26(21 \%)$ and $25(21 \%)$ cases, respectively. In 14 of these cases (56\%), gain of $1 \mathrm{q}$ and loss of $16 \mathrm{q}$ were the result of the unbalanced translocation $\mathrm{t}(1 ; 16)(\mathrm{q} 10 \sim 21 ; \mathrm{q} 10 \sim \mathrm{q} 13)$. Loss of whole chromosome 16 occurred in seven cases $(28 \%)$. Deletions of the short arm of chromosome 1 , with breakpoints ranging between 1p13-1p36.3, were found in 10 of the cases analysed $(8 \%)$. Other non-random aberrations found in cases analysed by classical cytogenetic and/or CGH analysis were gain of chromosomes 20 (12 cases, 13\%), 5 (12 cases, 12\%), 2 (11 cases, $11 \%), 7$ (10 cases, 10\%), and 14 (nine cases, 9\%). Isochromosomes of $8 \mathrm{q}$ were present in two cases, and in one case $\mathrm{i}(14)(\mathrm{q} 10)$ was found.

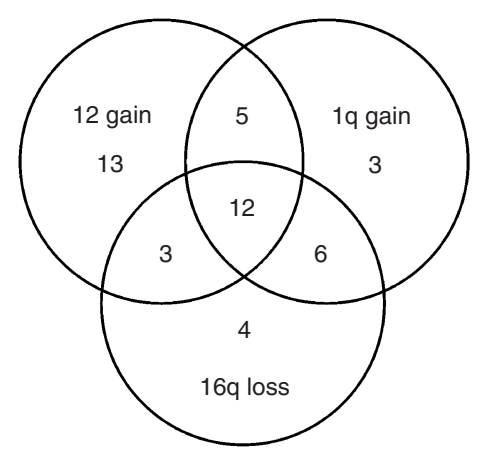

Figure I Distribution and interrelation of chromosome I 2 gain, I q gain and $16 \mathrm{q}$ loss in 46 out of 118 patients with Ewing tumours. None of these aberrations was found in Ewing tumours of 72 patients.

Table I Overall survival rates according to clinical parameters and genetic aberrations of all patients with ET and of patients with localised ET only

\begin{tabular}{|c|c|c|c|c|c|c|}
\hline \multirow[b]{2}{*}{ Parameters } & \multicolumn{3}{|c|}{ All patients with ET } & \multicolumn{3}{|c|}{ Patients with localised ET } \\
\hline & No. of pts ${ }^{a}$ & $\begin{array}{c}\text { 5-year survival } \\
\%(95 \% \mathrm{Cl})\end{array}$ & $P^{b}$ & No. of pts ${ }^{c}$ & $\begin{array}{c}\text { 5-year survival } \\
\%(95 \% \mathrm{Cl})\end{array}$ & $P^{b}$ \\
\hline \multicolumn{7}{|c|}{ Disease at diagnosis } \\
\hline localised & 91 & $72(60-8 I)$ & & & & \\
\hline disseminated & 43 & $49(32-65)$ & 0.003 & & & \\
\hline \multicolumn{7}{|l|}{ Tumor site } \\
\hline axial & 78 & $51(37-63)$ & & 50 & $61(43-74)$ & \\
\hline extremities & 56 & $82(69-90)$ & 0.005 & 41 & $86(70-94)$ & 0.029 \\
\hline \multicolumn{7}{|l|}{ Age } \\
\hline$<15$ years & 83 & $73(60-82)$ & & 60 & $78(64-87)$ & \\
\hline$\geqslant 15$ years & 51 & $51(34-66)$ & 0.065 & 31 & $61(40-77)$ & 0.244 \\
\hline \multicolumn{7}{|l|}{ Sex } \\
\hline male & 62 & $62(46-74)$ & & 37 & $66(47-81)$ & \\
\hline female & 72 & $67(54-77)$ & 0.623 & 54 & $76(60-86)$ & 0.415 \\
\hline \multicolumn{7}{|l|}{ Chromosome 8} \\
\hline 8 gain & 68 & $60(45-7 \mid)$ & & 43 & $74(56-86)$ & \\
\hline no gain & 63 & $7 \mid(55-8 \mid)$ & 0.249 & 46 & $69(52-81)$ & 0.326 \\
\hline \multicolumn{7}{|c|}{ Chromosome 12} \\
\hline 12 gain & 36 & $55(37-72)$ & & 23 & $60(38-78)$ & \\
\hline no gain & 95 & $67(55-77)$ & 0.222 & 65 & $75(6 \mid-85)$ & 0.226 \\
\hline \multicolumn{7}{|c|}{ Chromosomes 8 and 12} \\
\hline 8 gain & 41 & $60(42-73)$ & & 27 & $73(5 \mid-86)$ & \\
\hline $8+12$ gain & 26 & $57(36-76)$ & & 18 & $61(37-81)$ & \\
\hline 12 gain & 10 & $48(23-76)$ & & 5 & $53(20-87)$ & \\
\hline no gain & 52 & $75(58-85)$ & 0.136 & 37 & $77(57-88)$ & 0.599 \\
\hline \multicolumn{7}{|l|}{ Chromosome I } \\
\hline lq gain & 26 & $46(27-66)$ & & 14 & $53(29-77)$ & \\
\hline no gain & 98 & $72(59-8 \mid)$ & 0.002 & 69 & $78(63-87)$ & 0.029 \\
\hline \multicolumn{7}{|l|}{ Chromosome I } \\
\hline Ip deletion & 10 & $50(25-76)$ & & 6 & $50(22-81)$ & \\
\hline no deletion & 112 & $67(55-76)$ & 0.429 & 74 & $75(6 \mid-84)$ & 0.477 \\
\hline \multicolumn{7}{|c|}{ Chromosome 16} \\
\hline 16q loss & 25 & $43(24-64)$ & & 12 & $54(28-79)$ & \\
\hline no loss & 94 & $7 \mid(59-80)$ & 0.008 & 66 & $76(6 \mid-85)$ & 0.297 \\
\hline
\end{tabular}

${ }^{a}$ Number of all patients except those of whom tumours were not evaluated for the particular parameter. ${ }^{b} P$ values were calculated by the log-rank test. 'Number of patients with localised disease except those of whom tumours were not evaluated for the particular parameter. $\mathrm{Cl}=$ Confidence interval. 
Frequencies and interrelations of chromosome 12 gain, 1q gain, and $16 \mathrm{q}$ loss in 118 ETs evaluated for all three parameters are shown in Figure 1. The associations between these three genetic aberrations were statistically significant $(P<0.0001)$. Interestingly, gain of chromosome 8 was only associated with gain of chromosome $12(P<0.004)$. Seventy-two per cent of tumours with gain of chromosome 8 had also gain of chromosome 12 whereas only $44 \%$ of tumours with normal copy numbers of chromosome 8 had gain of chromosome 12. These associations were independent of whether the tumours were localised or disseminated. No association was found between $1 \mathrm{p}$ deletions and the other genetic parameters. The consistency of genetic data among the four countries was assessed by Chi-square analysis and no significant differences were detected ( $P>0.1$ for all analyses).

\section{Correlations between genetic aberrations and clinical parameters}

Associations between clinical parameters and genetic aberrations were found for $1 \mathrm{q}$ gain and $16 \mathrm{q}$ loss. Both aberrations correlated with age at diagnosis $\geqslant 15$ years $(34 \%$ vs $13 \%, P=0.005$ and $31 \%$ vs $15 \%, P=0.035)$. In the subgroup of patients with localised disease only $16 \mathrm{q}$ loss was still significantly associated with age $\geqslant 15$ years $(P=0.047)$. The presence of $16 \mathrm{q}$ loss was also signifi- cantly associated with disseminated disease at diagnosis $(32 \%$ vs $15 \%, P=0.038)$. Consistency among the four countries was seen for sex and tumour site $(P>0.1)$, but not for age at diagnosis $(P<0.0002)$. In Helsinki, more patients with an age older than 15 years at diagnosis were submitted compared to the other three centres.

\section{Analysis of overall and event-free survival}

The median duration of follow-up for surviving patients was 5 years (range 8 months - 15 years). Five-year OS and EFS rates for all ET patients included for statistical analysis and for the subgroup of patients with localised ET at diagnosis are summarised in Tables 1 and 2. Patients with localised disease at diagnosis showed better OS than patients with disseminated disease $(P=0.003)$. Univariate analysis of OS and EFS estimates revealed that tumour site was a predictive factor for $O S$ as patients with axial tumours had poorer outcomes $(P=0.005$ and $P=0.029$ ).

Among the five genetic parameters tested, only gain of $1 \mathrm{q}$ was a predictive factor for both adverse OS and EFS either in the total group of patients (Figure 2A,B and Tables 1 and 2) as well as in the subgroup of patients with localised disease (Table 2). Loss of $16 \mathrm{q}$ was significantly associated with adverse OS $(P=0.008)$

Table 2 Event-free survival rates according to clinical parameters and genetic aberrations of patients with ET and of patients with localised ET only

\begin{tabular}{|c|c|c|c|c|c|c|}
\hline \multirow[b]{2}{*}{ Parameters } & \multicolumn{3}{|c|}{ All patients with ET } & \multicolumn{3}{|c|}{ Patients with localised ET } \\
\hline & No. of pts ${ }^{a}$ & $\begin{array}{l}\text { 5-year EFS } \\
\%(95 \% \mathrm{Cl})\end{array}$ & $P^{b}$ & No. of pts ${ }^{c}$ & $\begin{array}{l}\text { 5-year EFS } \\
\%(95 \% \mathrm{Cl})\end{array}$ & $P^{\mathbf{b}}$ \\
\hline \multicolumn{7}{|c|}{ Disease at diagnosis } \\
\hline localised & 78 & $56(4 \mid-68)$ & & & & \\
\hline disseminated & 31 & $35(16-56)$ & 0.069 & & & \\
\hline \multicolumn{7}{|l|}{ Tumor site } \\
\hline & 67 & $41(24-55)$ & & 44 & $5 \mid(3 \mid-68)$ & \\
\hline extremities & 42 & $62(44-76)$ & 0.147 & 34 & $60(41-76)$ & 0.588 \\
\hline \multicolumn{7}{|l|}{ Age } \\
\hline$<15$ years & 63 & $56(40-69)$ & & 49 & $60(42-74)$ & \\
\hline$\geqslant 15$ years & 46 & $42(25-58)$ & 0.116 & 29 & $50(28-68)$ & 0.302 \\
\hline \multicolumn{7}{|l|}{ Sex } \\
\hline male & 50 & $46(27-63)$ & & 32 & $51(29-69)$ & \\
\hline female & 59 & $53(38-66)$ & 0.758 & 46 & $59(41-74)$ & 0.923 \\
\hline \multicolumn{7}{|l|}{ Chromosome 8} \\
\hline 8 gain & 50 & $59(40-73)$ & & 38 & $64(42-78)$ & \\
\hline no gain & 58 & $42(27-57)$ & 0.148 & 39 & $48(30-65)$ & 0.263 \\
\hline \multicolumn{7}{|c|}{ Chromosome 12} \\
\hline 12 gain & 29 & $46(26-66)$ & & 20 & $37(|8-6|)$ & \\
\hline no gain & 78 & $52(37-65)$ & 0.393 & 56 & $64(46-76)$ & 0.009 \\
\hline \multicolumn{7}{|c|}{ Chromosomes 8 and 12} \\
\hline 8 gain & 33 & $42(23-60)$ & & 22 & $58(33-77)$ & \\
\hline $8+12$ gain & 24 & $48(25-70)$ & & 16 & $40(18-67)$ & \\
\hline 12 gain & 5 & $40(12-77)$ & & 4 & $25(7-70)$ & \\
\hline no gain & 45 & $60(40-75)$ & 0.287 & 34 & $68(45-83)$ & 0.037 \\
\hline \multicolumn{7}{|l|}{ Chromosome I } \\
\hline lq gain & 23 & $39(21-60)$ & & 13 & $36(16-63)$ & \\
\hline no gain & 81 & $56(40-68)$ & 0.018 & 60 & $65(47-78)$ & 0.010 \\
\hline \multicolumn{7}{|l|}{ Chromosome I } \\
\hline Ip deletion & 9 & $33(12-65)$ & & 6 & $33(12-70)$ & \\
\hline no deletion & 92 & $53(38-64)$ & 0.246 & 64 & $60(43-73)$ & 0.153 \\
\hline \multicolumn{7}{|c|}{ Chromosome 16} \\
\hline $16 q$ loss & 21 & $38(19-62)$ & & 11 & $38(16-68)$ & \\
\hline no loss & 78 & $74(38-66)$ & 0.092 & 57 & $61(43-74)$ & 0.151 \\
\hline
\end{tabular}

${ }^{a}$ Number of all patients except those of whom tumours were not evaluated for the particular parameter. ${ }^{b} P$ values were calculated by the log-rank test. 'Number of patients with localised disease except those of whom tumours were not evaluated for the particular parameter. $\mathrm{Cl}=$ Confidence interval. 
A

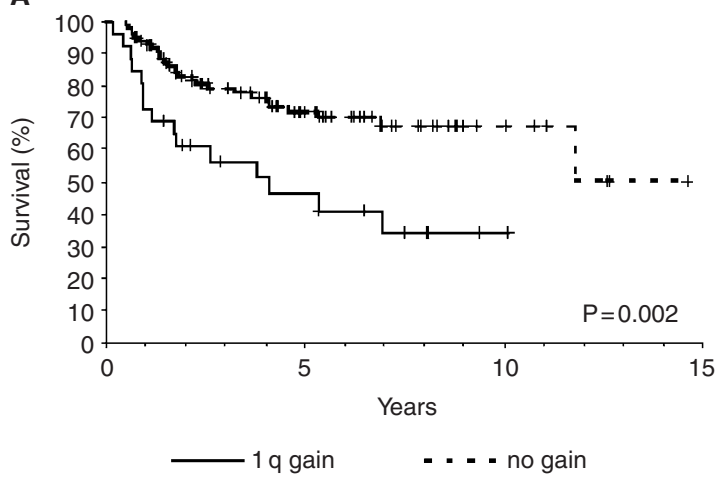

C

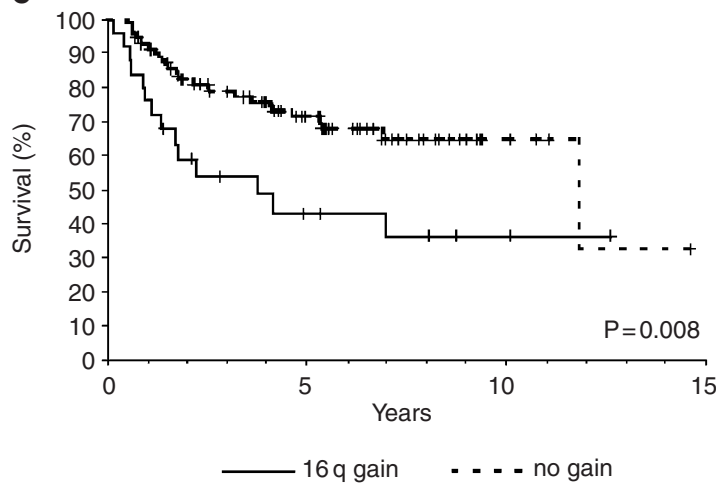

B

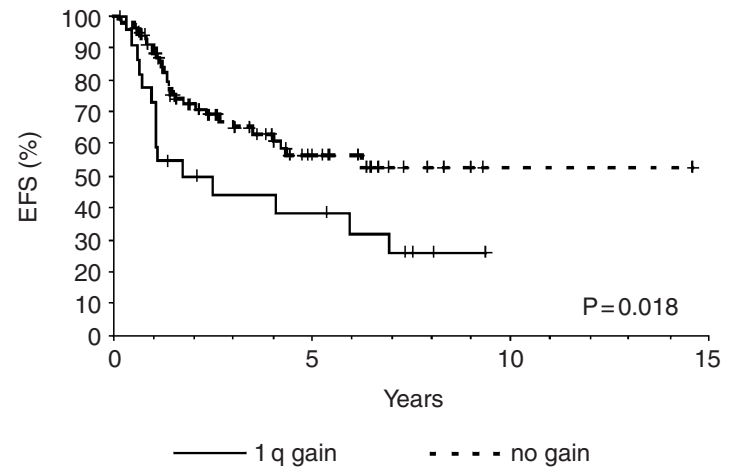

D

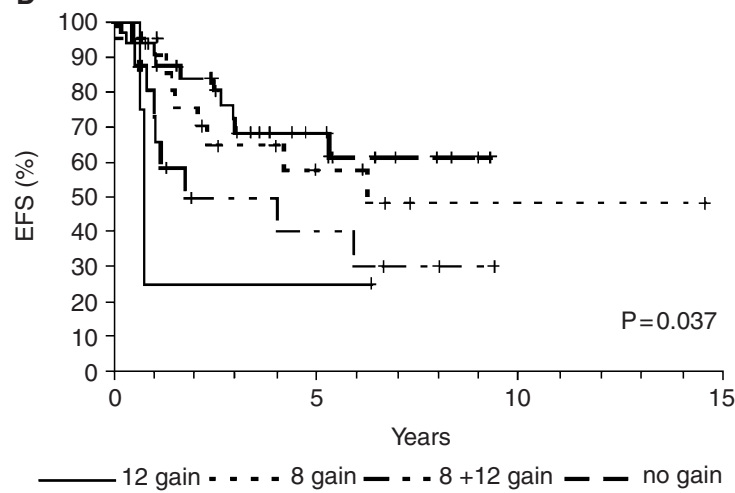

Figure 2 Overall survival plots $(\mathbf{A}$ and $\mathbf{C})$ and event-free survival plots (EFS) (B and $\mathbf{D})$ for patients with Ewing tumours displaying $(\mathbf{A})$ I $q$ gain $(n=26)$ or balanced ratios between I $p$ and I $(n=98)$, (B) I q gain $(n=23)$ or balanced ratios between I $p$ and I $\mathrm{q}(n=8 \mathrm{I}),(\mathbf{C})$ I $6 \mathrm{q}$ loss $(n=25)$ or normal copy number of chromosome $16(n=94)$, and (D) gain of chromosome $8(n=22)$, gain of chromosomes 8 and $12(n=16)$, gain of chromosome 12 ( $n=4)$ or normal copy numbers of chromosomes 8 and $12(n=34)$.

(Figure 2C) but not with EFS in all patients, and did not show significant associations with outcome in the subgroup of patients with localised disease. In contrast, gain of chromosome 8 was not associated with clinical outcome in all evaluations. However, in patients with localised disease, gain of chromosome 12 was significantly associated with poorer EFS $(P=0.009)$ and combined analysis of gain of chromosomes 8 and/or 12 identified four groups of patients with localised disease and statistically significant different EFS rates (Figure 2D).

In the multivariate model, gain of 1q maintained its significant impact on survival $(\mathrm{RHR}=2, P=0.046)$ after adjustment for clinical parameters. This was also true for loss of $16 \mathrm{q}(\mathrm{RHR}=1.9, P=0.060)$. In a stepwise selection procedure only gain of $1 \mathrm{q}$ met the $25 \%$ level for entry into the model, which was expected because of the high correlation seen between gain of $1 \mathrm{q}$ and loss of $16 \mathrm{q}$.

\section{DISCUSSION}

In the present study, genetic and clinical data from 134 patients with skeletal and extraskeletal ETs were collected from four centres in order to determine whether chromosomal aberrations present in addition to $22 \mathrm{q} 12$ rearrangements are of prognostic significance. Diagnosis of ET was confirmed by high expression of the CD99 antigen and/or the presence of a 22q12 rearrangement. Tumour samples were analysed using a combination of classical cytogenetic analysis, FISH, CGH and/or RT-PCR.

In this series, evidence for $22 \mathrm{q} 12$ rearrangements was present in $98 \%$ of the cases analysed. Notably, as only $13 \%$ (11 out of 85 ) of the cytogenetically analysed cases did not display chromosomal aberrations in addition to a $22 \mathrm{q} 12$ rearrangement, this illustrates the importance of genetic analysis by complementary techniques to detect these additional genetic events. When compiling the data of all samples analysed, gain of chromosome 8 was found in $52 \%$ and of chromosome 12 in $28 \%$ of the cases. Gains of chromosomes $20,5,2,7$ and 14 were found in decreasing frequency in less than $14 \%$ of the cases and thus the results of the present study are consistent with previous studies (Kullendorff et al, 1999). The most frequent facultative structural aberrations were gains of 1q and loss of $16 \mathrm{q}$ that were present in $21 \%$ each. The majority displayed one or two $\operatorname{der}(16) \mathrm{t}(1 ; 16)$ chromosomes, thus having a genetic net imbalance of 1q gain and 16q loss, which was a statistically significant association. In addition, chromosome 12 gain was associated with gain of $1 \mathrm{q}$ and loss of $16 \mathrm{q}$, but there was a relatively low frequency of ETs that displayed 1q gain and/or 16q loss that did not have gain of chromosome 12 . These data suggest that tumours with gain of chromosome 12 might have a tendency towards acquiring structural alterations involving $1 \mathrm{q}$ and $16 \mathrm{q}$ and that these structural chromosomal aberrations occur later than numerical aberrations. Interestingly, although gain of chromosome 8 was the most frequent numerical aberration, it was only significantly associated with gain of chromosome 12 in this study. Deletions at $1 \mathrm{p}$ were not associated with one of the other frequent aberrations, although this is possibly due to deletions at $1 \mathrm{p}$ being present in only $8 \%$ of the cases analysed.

Previous studies have shown that the presence of metastases at onset is the main adverse prognostic parameter for patients with ET (Jürgens et al, 1988; Terrier et al, 1996; Cotterill et al, 2000). In the present study, disseminated disease at diagnosis and axial tumour site were significantly associated with adverse OS, although not with EFS. Among the genetic parameters evaluated for prog- 
nostic clinical impact gain of $1 \mathrm{q}$ was a strong predictor for adverse OS and EFS both in patients with localised disease and in the entire study group. Gain of $1 \mathrm{q}$ has also been reported to be associated with advanced disease stage in two other childhood tumours, neuroblastoma (Hirai et al, 1999) and Wilms' tumour (Hing et al, 2001). 1q is known to contain several genes that might contribute to the development and/or progression of human sarcoma (Forus et al, 1998; Knuutila et al, 1998). Loss of 16q correlated significantly with adverse OS in the entire study group but not in the subgroup of patients with localised disease. This observation could be due to the fact that $16 \mathrm{q}$ loss was significantly associated with disseminated disease at diagnosis. However, the biological consequences of $1 \mathrm{q}$ gain and $16 \mathrm{q}$ loss remain to be elucidated. Gains of chromosomes 8 and 12 for which trends toward worse outcome have been reported (Armengol et al, 1997; Tarkkanen et al, 1999) were not predictive factors for OS and EFS in the entire study group. In contrast, within the group of patients with localised ET gain of chromosome 12 identified a subgroup of patients with markedly poor clinical outcome.

Molecular studies have suggested that TP53 alterations (de Alava et al, 2000), INK4A deletions (Wei et al, 2000), and type of the EWS/FLI1 fusion transcript (Zoubek et al, 1994, 1996; de Alava et al, 1998) are predictive prognostic factors in ETs. Unfortunately, no study currently exists that provides molecular, cytogenetic, histopathological and clinical data of a series of patients large enough for statistical evaluation. The present study has shown that data from a series of 134 ET patients compiled from four different countries and obtained by complementary techniques enabled the

\section{REFERENCES}

Ahrens S, Hoffmann C, Jabar S, Braun MG, Paulussen M, Dunst J, Rube C, Winkelmann W, Heinecke A, Göbel U, Winkler K, Harms D, Treuner J, Jürgens H (1999) Evaluation of prognostic factors in a tumor volumeadapted treatment strategy for localized Ewing sarcoma of bone: the CESS 86 experience. Cooperative Ewing Sarcoma Study. Med Pediatr Oncol 32: $186-195$

Akaike H (1972) Use of an information theoretic quantity for statistical model identification. Proceedings of the Fifth Hawai International Conference on System Sciences. Western Periodically, North Hollywood, CA, USA

Ambros IM, Ambros PF, Strehl S, Kovar H, Gadner H, Salzer-Kuntschik M (1991) MIC2 is a specific marker for Ewing's sarcoma and peripheral primitive neuroectodermal tumors. Evidence for a common histogenesis of Ewing's sarcoma and peripheral primitive neuroectodermal tumors from MIC2 expression and specific chromosome aberration. Cancer 67: $1886-1893$

Ambros PF, Ambros IM, Strehl S, Bauer S, Luegmayr A, Kovar H, Ladenstein R, Fink FM, Horcher E, Printz G, Mutz I, Schilling F, Urban C, Gadner H (1995) Regression and progression in neuroblastoma. Does genetics predict tumour behaviour? Eur J Cancer 31A: 510-515

Armengol G, Tarkkanen M, Virolainen M, Forus A, Valle J, Böhling T, AskoSeljavaara SS, Blomqvist C, Elomaa I, Karaharju E, Kivioja AH, Siimes MA, Tukiainen E, Caballin MR, Myklebost O, Knuutila S (1997) Recurrent gains of 1q, 8 and 12 in the Ewing family of tumours by comparative genomic hybridization. Br J Cancer 75: 1403-1409

Aurias A, Rimbaut C, Buffe D, Dubousset J, Mazabraud A (1983) Chromosomal translocations in Ewing's sarcoma. N Engl J Med 309: 496-497

Bacci G, Ferrari S, Bertoni F, Rimondini S, Longhi A, Bacchini P, Forni C, Manfrini M, Donati D, Picci P (2000) Prognostic factors in nonmetastatic Ewing's sarcoma of bone treated with adjuvant chemotherapy: analysis of 359 patients at the Istituto Ortopedico Rizzoli. J Clin Oncol 18: 4-11

Becroft DM, Pearson A, Shaw RL, Zwi LJ (1984) Chromosome translocation in extraskeletal Ewing's tumour. Lancet 2: 400

Cotterill SJ, Ahrens S, Paulussen M, Jurgens HF, Voute PA, Gadner H, Craft AW (2000) Prognostic factors in Ewing's tumor of bone: analysis of 975 patients from the European Intergroup Cooperative Ewing's Sarcoma Study Group. J Clin Oncol 18: 3108-3114

Cox D (1972) Regression models and life-tables (with discussion). J Royal Stat Soc 34: $187-220$ identification of $1 \mathrm{q}$ gain as a negative prognostic marker for patients with ET regardless of stage of disease. In addition, loss of $16 \mathrm{q}$ is the first genetic parameter that is associated significantly with disseminated disease at onset. Therefore, the copy number of $1 \mathrm{q}$ and $16 \mathrm{q}$ should be evaluated in addition to the presence of a $22 \mathrm{q} 12$ rearrangement in ETs to identify patients with a higher probability of adverse outcome.

\section{ACKNOWLEDGEMENTS}

The authors are indebted to the Universitätskinderklinik Graz, Universitätsklinik für Kinderheilkunde Innsbruck, Landeskrankenhaus Klagenfurt, Landeskinderklinik Linz, Kinderspital Salzburg, St. Anna Kinderspital and the Institute of Clinical Pathology Vienna (all Austria); the Olgahospital Stuttgart (Germany); the SCMCJ Tel Aviv (Israel); Universitätskinderklinik Basel, Hopital des Enfants HCUG Geneva, Kantonssspital St. Gallen, Kinderspital St. Gallen, Universtätsspital Zürich, Stadtspital Treimli Zürich, Universitätskinderklinik Zürich (all Switzerland) for providing tumour samples and clinical data; and to G Thomas and O Delattre (Institut Curie, Paris, France) for providing cosmid clones flanking the EWS breakpoint region. This study was financially supported by the Forschungsinstitut für Krebskranke Kinder im St. Anna Kinderspital, the Hospital for Sick Children Foundation, the Leiras Research Foundation, the Österreichische Kinder-Krebs-Hilfe, the Paulo Foundation and the Schweizer Forschungsstiftung Kind und Krebs. de Alava E, Antonescu CR, Panizo A, Leung D, Meyers PA, Huvos AG, Pardo-Mindan FJ, Healey JH, Ladanyi M (2000) Prognostic impact of P53 status in Ewing sarcoma. Cancer 89: 783-792

de Alava E, Kawai A, Healey JH, Fligman I, Meyers PA, Huvos AG, Gerald WL, Jhanwar SC, Argani P, Antonescu CR, Pardo MF, Ginsberg J, Womer R, Lawlor ER, Wunder J, Andrulis I, Sorensen PH, Barr FG, Ladanyi M (1998) EWS-FLI1 fusion transcript structure is an independent determinant of prognosis in Ewing's sarcoma. J Clin Oncol 16: 1248-1255

Delattre O, Zucman J, Melot T, Garau XS, Zucker JM, Lenoir GM, Ambros PF, Sheer D, Turc-Carel C, Triche TJ, Aurias A, Thomas G (1994) The Ewing family of tumors - a subgroup of small-round-cell tumors defined by specific chimeric transcripts. N Engl J Med 331: 294-299

Delattre O, Zucman J, Plougastel B, Desmaze C, Melot T, Peter M, Kovar H, Joubert I, De JP, Rouleau G, Aurias A, Thomas G (1992) Gene fusion with an ETS DNA-binding domain caused by chromosome translocation in human tumours. Nature 359: $162-165$

Desmaze C, Zucman J, Delattre O, Melot T, Thomas G, Aurias A (1994) Interphase molecular cytogenetics of Ewing's sarcoma and peripheral neuroepithelioma $t(11,22)$ with flanking and overlapping cosmid probes. Cancer Genet Cytogenet 74: 13-18

Dorey FJ, Korn EL (1987) Effective sample sizes for confidence intervals for survival probabilities. Stat Med 6: 679-687

Douglass EC, Rowe ST, Valentine M, Parham D, Meyer WH, Thompson EI (1990) A second nonrandom translocation, $\operatorname{der}(16) \mathrm{t}(1,16)(\mathrm{q} 21, \mathrm{q} 13)$, in Ewing sarcoma and peripheral neuroectodermal tumor. Cytogenet Cell Genet 53: $87-90$

Dracopoli NC (2001) Current protocols in human genetics. In Cytogenetics Volume 1 Chapter 4 Dracopoli NC, Haines JL, Korf BR, Moir DT, Morton CC, Seidman CE, Seidman JG, Smith DR (eds). New York: John Wiley \& Sons

Elomaa I, Blomqvist C, Sæter G, Åkerman M, Stenwig E, Wiebe T, Björk O, Alvegård TA (2000) Five-year results in Ewing's sarcoma. The Scandinavian Sarcoma Group experience with the SSG IX protocol. Eur J Cancer 36: $875-880$

Forus A, Berner JM, Meza-Zepeda LA, Saeter G, Mischke D, Fodstad O, Myklebost O (1998) Molecular characterization of a novel amplicon at 1q21-q22 frequently observed in human sarcomas. Br J Cancer 78: $495-$ 503 
Hattinger CM, Rumpler S, Ambros IM, Strehl S, Lion T, Zoubek A, Gadner $\mathrm{H}$, Ambros PF (1996) Demonstration of the translocation $\operatorname{der}(16) \mathrm{t}(1,16)(\mathrm{q} 12, \mathrm{q} 11.2)$ in interphase nuclei of Ewing tumors. Genes Chromosomes Cancer 17: $141-150$

Hattinger CM, Rumpler S, Strehl S, Ambros IM, Zoubek A, Pötschger U, Gadner H, Ambros PF (1999) Prognostic Impact of Deletions at 1p36 and Numerical Aberrations in Ewing Tumors. Genes Chromosomes Cancer 24: $243-254$

Hattinger CM, Zoubek A, Ambros PF (2000) Molecular cytogenetics in Ewing tumors diagnostic and prognostic information. Onkologie 23: $416-422$

Hing S, Lu Y-J, Summersgill B, King-Underwood L, Nicholson J, Grundy P, Grundy R, Gessler M, Shipley J, Pritchard-Jones K (2001) Gain of 1q is associated with adverse outcome in favorable histology Wilms' tumors. Am J Pathol 158: 393-398

Hirai M, Yoshida S, Kashiwagi H, Kawamura T, Ishikawa T, Kaneko M, Ohkawa H, Nakagawara A, Miwa M, Uchida K (1999) 1q23 gain is associated with progressive neuroblastoma resistant to aggressive treatment. Genes Chromosomes Cancer 25: $261-269$

ISCN (1995) An International System for Human Cytogenetic Nomenclature. Mitelman F (ed) Basel: S Karger

Jürgens H (1994) Ewing's sarcoma and peripheral primitive neuroectodermal tumor. Curr Opin Oncol 6: 391-396

Jürgens H, Exner U, Gadner H, Harms D, Michaelis J, Sauer R, Treuner J, Voute PA, Winkelmann W, Winkler K, Göbel U (1988) Multidisciplinary treatment of primary Ewing's sarcoma of bone: a 6-year experience of a European cooperative trial. Cancer 61: 23-32

Kaplan EL, Meier P (1958) Nonparametric estimation from incomplete observations. J Am Stat Assoc 53: 457-481

Knuutila S, Bjöorkqvist AM, Autio K, Tarkkanen M, Wolf M, Monni O, Szymanska J, Larramendy ML, Tapper J, Pere H, El-Rifai W, Hemmer S, Wasenius VM, Vidgren V, Zhu Y (1998) DNA copy number amplifications in human neoplasms. Am J Pathol 152: 1107-1123

Koscielniak E, Jürgens H, Winkler K, Burger D, Herbst M, Keim M, Bernhard G, Treuner J (1992) Treatment of soft tissue sarcoma in childhood and adolescence. A report of the German Cooperative Soft Tissue Sarcoma Study. Cancer 70: $2557-2567$

Kovar H, Jug G, Aryee DNT, Zoubek A, Ambros PF, Gruber B, Windhager R, Gadner H (1997) Among genes involved in the RB dependent cell cycle regulatory cascade, the p16 tumor suppressor gene is frequently lost in the Ewing family of tumors. Oncogene 15: 2225-2232

Kullendorff CM, Mertens F, Donner M, Wiebe T, Akerman M, Mandahl N (1999) Cytogenetic aberrations in Ewing sarcoma: are secondary changes associated with clinical outcome? Med Pediatr Oncol 32: 79-83

Maurici D, Perez AA, Grier HE, Baldini N, Serra M, Fletcher JA (1998) Frequency and implications of chromosome 8 and 12 gains in Ewing sarcoma. Cancer Genet Cytogenet 100: 106-110

Miser JS, Kinsella T, Triche TJ, Tsokos M, Jarosinski P, Forquer R, Wesley R, Magrath I (1987) Ifosfamide with mesna uroprotection and etoposide: an effective regimen in the treatment of recurrent sarcomas and other tumors of children and young adults. J Clin Oncol 5: 1191-1198

Mitelman F, Johansson B, Mertens F (2001) Mitelman database of chromosome aberrations in cancer. Mitelman F, Johansson B, Mertens F (eds). http://cgap.nci.nih.gov/Chromosomes/Mitelman
Mugneret F, Lizard S, Aurias A, Turc-Carel C (1988) Chromosomes in Ewing's sarcoma. II. Nonrandom additional changes, trisomy 8 and der(16)t $(1,16)$. Cancer Genet Cytogenet 32: $239-245$

Picci P, Böhling T, Bacci G, Ferrari S, Sangiorgi L, Mercuri M, Ruggieri P, Manfrini M, Ferraro A, Casadei R, Benassi MS, Mancini AF, Rosito P, Cazzola A, Barbieri E, Tienghi A, Brach-del PA, Comandone A, Bacchini P, Bertoni $\mathrm{F}$ (1997) Chemotherapy-induced tumor necrosis as a prognostic factor in localized Ewing's sarcoma of the extremities. J Clin Oncol 15: $1553-1559$

Sandberg AA, Bridge JA (2000) Updates on cytogenetics and molecular genetics of bone and soft tissue tumors: Ewing sarcoma and peripheral primitive neuroectodermal tumors. Cancer Genet Cytogenet 123: 1-26

Stark B, Mor C, Jeison M, Gobuzov R, Cohen IJ, Goshen Y, Stein J, Fisher S, Ash S, Yaniv I, Zaizov R (1997) Additional chromosome 1q aberrations and $\operatorname{der}(16) \mathrm{t}(1,16)$, correlation to the phenotypic expression and clinical behavior of the Ewing family of tumors. J Neurooncol 31: 3-8

Tarkkanen M, Kiuru-Kuhlefelt S, Blomqvist C, Armengol G, Böhling T, Ekfors T, Virolainen M, Lindholm P, Monge O, Picci P, Knuutila S, Elomaa I (1999) Clinical correlations of genetic changes by comparative genomic hybridization in Ewing sarcoma and related tumors. Cancer Genet Cytogenet 114: $35-41$

Terrier P, Llombart-Bosch A, Contesso G (1996) Small round blue cell tumors in bone: prognostic factors correlated to Ewing's sarcoma and neuroectodermal tumors. Semin Diagn Pathol 13: 250 - 257

Turc-Carel C., Philip I, Berger MP, Philip T, Lenoir GM (1983) Chromosomal translocations in Ewing's sarcoma. N Engl J Med 309: 497-498

Wei G, Antonescu CR, de Alava E, Leung D, Huvos AG, Meyers PA, Healey JH, Ladanyi M (2000) Prognostic impact of INK4A deletion in Ewing sarcoma. Cancer 89: 793 - 799

Whang-Peng J, Triche TJ, Knutsen T, Miser J, Douglass EC, Israel MA (1984) Chromosome translocation in peripheral neuroepithelioma. $N$ Engl J Med 311: $584-585$

Wiklund TA, Blomqvist CP, Virolainen M, Elomaa I (1992) Ifosfamide, vincristine, doxorubicin and dacarbazine in adult patients with advanced sot-tissue sarcoma. Cancer Chemother Pharmacol 30: 100-104

Zielenska M, Zhang ZM, Ng K, Marrano P, Bayani J, Ramirez OC, Sorensen P, Thorner P, Greenberg M, Squire J (2001) Acquisition of secondary structural chromosomal changes in pediatric Ewing's sarcoma is a probable prognostic factor for tumor response and clinical outcome. Cancer 91: $2156-2164$

Zoubek A, Dockhorn DB, Delattre O, Christiansen H, Niggli F, Gatterer MI, Smith TL, Jurgens H, Gadner H, Kovar H (1996) Does expression of different EWS chimeric transcripts define clinically distinct risk groups of Ewing tumor patients? J Clin Oncol 14: 1245-1251

Zoubek A, Pfleiderer C, Salzer KM, Amann G, Windhager R, Fink FM, Koscielniak E, Delattre O, Strehl S, Ambros PF, Gadner $\mathrm{H}$, Kovar $\mathrm{H}$ (1994) Variability of EWS chimaeric transcripts in Ewing tumours: a comparison of clinical and molecular data. Br J Cancer 70: 908-913

Zucman J, Delattre O, Desmaze C, Plougastel B, Joubert I, Melot T, Peter M, De JP, Rouleau G, Aurias A, Thomas G (1992) Cloning and characterization of the Ewing's sarcoma and peripheral neuroepithelioma $t(11,22)$ translocation breakpoints. Genes Chromosomes Cancer 5: 271-277 